\title{
The self- versus full-service decision: Gender-based differences in assessment of risk
}

Received (in revised form): 28th March, 2002

\section{Julie Z. Sneath}

is an associate professor in the Business Division at LaGrange College. Her primary research interests are in consumer behaviour and sport and event marketing. A former sales manager for an international firm, her research has been published in the Journal of Shopping Center Research, Journal of Customer Service in Marketing and Management and International Sports Journal.

\section{Pamela A. Kennett}

is an assistant professor in the Department of Marketing at the University of New Orleans. Her current research interests lie in the areas of sport and event marketing, particularly the determinants of fan satisfaction and evaluation of sponsorship effectiveness and services marketing. Her work appears in journals such as the Journal of Business Research, Journal of Services Marketing and Journal of Customer Service in Marketing and Management in addition to numerous conference proceedings.

\section{Carol M. Megehee}

is an assistant professor of marketing in the Mitchell College of Business, University of South Alabama, Mobile, Alabama. Dr Megehee's research and teaching interests include services marketing, marketing communications and channel marketing. Dr Megehee's research has been published in the International Journal of Value-Based Management, Transportation Research Forum, Public Utilities Fortnightly and Society of Marketing Advances Proceedings.

Julie Z. Sneath Division of Business and Economics, LaGrange College, 601 Broad Street, LaGrange, GA 30240, USA

Tel: +1 7068808255 ; Fax: +17068808019 ; e-mail: jsneath@lgc.edu

\begin{abstract}
Service is largely becoming self-service for the average consumer. Many full-service providers have begun to offer self-service options to their customers, or are replacing current offerings. Because of the potential for negative outcomes, including reduced customer loyalty and increased opportunities for competitors, managers need to understand what motivates individuals to choose between self- and full-service options. The results of the research indicate that gender-based differences in consumer perceptions of risk influence the self- versus full-service decision. Using the selectivity model of information processing, it is shown that men and women differ in the number and components of risk used to make a choice decision. Findings also suggest that components of risk associated with both self- and full-service options are evaluated prior to making the choice between self- and full-service modes of delivery.
\end{abstract}

\section{INTRODUCTION}

The service economy has evolved into one in which standard full customer service has been supplemented with, or supplanted by, self-service modes of delivery. ${ }^{1,2}$ Many companies have reduced customer service, requiring that certain customers do more for themselves. The trade-off between short-term cost savings and long-term profitability is, however, unclear. Self-service options may lead to decline in perceptions of service quality and long-term dissatisfaction among customers. $^{3,4}$

Initially, increased productivity through self-service involved changing consumer expectations. ${ }^{5}$ But today's consumers are 
often willing to perform a service for themselves, even though it is not fully understood why they choose to do so. Certain individuals appear to perceive value in performing a service, rather than paying others to perform it on their behalf. Preference for self-service transactions has been attributed to the intrinsic motivations received by doing things for oneself. ${ }^{6}$ Although the choice between self- and full-service may not be dichotomous (ie should be viewed as a continuum whereby the consumer can choose between varying degrees of effort), the choice between self- and full-service exchange has been shown to be dependent upon individuals' expertise, resource capacity, available time, economic rewards, psychic rewards, trust and control. ${ }^{7}$

\section{SERVICES AND RISK}

Consumption decisions for services are perceived as being riskier than those for tangible goods. ${ }^{8-10}$ Despite the importance of the risk construct in the services literature, however, its relationship with the choice between self- versus full-service options is unclear. While it is likely that most consumers will choose the service option they perceive as being less risky, that is, engage in risk-reducing strategies in situations where risk is perceived to exist, individual differences may influence perceptions of apparent risk and, ultimately, preference for a service option. ${ }^{11}$

Choice among consumption options usually contains some element of 'uncertainty, or risk'. ${ }^{12}$ Indeed, a considerable body of research suggests that assessment of risk and the strategies used to reduce risk-induced anxiety vary across individuals and situations. Although perceptions of risk differ, overall, services are perceived as being riskier than tangible goods. ${ }^{13-15}$ Consequently, individuals' assessments of services-related risk could explain why some would be more likely to choose self-service over full-service options (and vice versa).

\section{GENDER AND RISK}

Research suggests that women are less likely than men to take risks, and when risk is perceived as being present women's decisions tend to be more conservative than those of their male counterparts. ${ }^{16,17}$ It has been suggested that gender-based differences in risk-taking propensity are a consequence of sociological (eg social roles) and/or biological (eg brain functioning) sources. ${ }^{18-22}$

Although an individual's perception of risk is 'subjective, as is perception of information', the manner in which risk is perceived and information evaluated is also a consequence of gender. ${ }^{23}$

According to the selectivity model, men and women process information differently. ${ }^{24-26}$ In general, men are likely to make decisions based on evaluation of one or more salient cues in the environment. Women, on the other hand, are more likely to make decisions based on the comprehensive processing of all available information. ${ }^{27}$ Women are also more likely than men to notice subtle situational differences. ${ }^{28}$

\section{PURPOSE OF THE STUDY}

This study examines the relationship between gender, risk assessment and likelihood of preference for self- versus full-service alternatives. Utilising dimensions of risk previously shown to influence choice - financial risk, performance risk, psychological risk, social risk, physical risk, time loss risk and overall risk — the study's objectives 
are to determine the impact of these risk dimensions on consumers' likelihood of choosing self- versus full-service alternatives, identify gender-based differences in evaluation of service options, and develop recommendations regarding gender-based segmentation strategies for service-oriented organisations. ${ }^{29-32}$

\section{HYPOTHESISED RELATIONSHIPS}

Risk has been shown to influence exchange decisions. According to Lusch and his colleagues, the choice between producing a service for oneself and having someone else perform the service is dependent on the individual's expertise, resources, time, economic rewards, psychic rewards, trust and control. ${ }^{33}$ Since risk is also believed to have an effect on choice, the risk associated with a transaction could explain why some individuals would choose one mode of service delivery over another.

According to Taylor, two types of uncertainty are involved in consumers' choice decisions: uncertainty about the outcome of a decision and uncertainty about the consequences of making a mistake. ${ }^{34}$ Individuals acquire and evaluate information to reduce uncertainty about an outcome, and reduce consequences by limiting risks. When making choice decisions, risk may be evaluated in terms of both gains and losses. Although the significance of each varies depending on the situation, both types of uncertainty are believed to be present every time a choice is made. Further, while consumers have been shown to "use "cues" as surrogates for desired information', it is likely that individuals will weigh the outcomes and consequences of both options - selfand full-service - when making a choice. ${ }^{35}$ Consequently, the following relationship is proposed:
H1a: Individuals who are likely to choose the self-service option will evaluate dimensions of risk associated with both self- and full-service options.

H1b: Individuals who are likely to choose the full-service option will evaluate dimensions of risk associated with both self- and full-service options.

Gender-based research on information processing suggests that men and women consider different information from the environment when making judgments. Specifically, men are likely to select a limited number of 'highly available cues', while women are likely to engage in extensive processing of all available information. ${ }^{36}$ Although processing differences between men and women may lessen under certain situations (eg in the presence of incongruous cues, both men and women are likely to engage in comprehensive information processing), the selectivity model suggests that, in general, men use a limited number of cues as a basis for judgment. This model provides support for the second hypothesised relationship:

H2a: Men who are likely to choose the self-service option will evaluate fewer dimensions of risk than women who are likely to choose the self-service option.

H2b: Men who are likely to choose the full-service option will evaluate fewer dimensions of risk than women who are likely to choose the full-service option.

Differences predicted by the selectivity model also indicate that the specific cues used by men to make judgments differ from those used by women. Research suggests that men rely upon 'heuristics devices that serve as surrogates for more 
The self- versus full-service decision: Gender-based differences in assessment of risk

Table 1: Completed questionnaires by scenario

\begin{tabular}{lcc}
\hline Scenario & Completed & Response rate (\%) \\
\hline Airport baggage & 23 & 76.7 \\
Bank withdrawal & 22 & 73.3 \\
Personal shopper & 26 & 86.6 \\
Map/directions & 21 & 70.0 \\
Gasoline & 24 & 80.0 \\
Grocery & 23 & 76.7 \\
Hair colour & 21 & 70.0 \\
Laundry (shirts) & 22 & 73.3 \\
Lawncare & 20 & 66.7 \\
Cholesterol test & 18 & 60.0 \\
Vend/In-room & 22 & 73.3 \\
Buffet/waiter & 20 & 66.7 \\
Photocopying & 15 & 50.0 \\
Tax preparation & 20 & 66.7 \\
Travel plans & 18 & 60.0 \\
Total & 315 & 70.0 \\
\hline
\end{tabular}

detailed processing, ${ }^{37}$ Women, on the other hand, are likely to evaluate all of the relevant information that is available. Consequently, it is likely that men and women evaluate different dimensions of risk when making judgments about selfand full-service alternatives. This suggests the final hypothesised relationship:

H3a: Men who are likely to choose the self-service option will evaluate different dimensions of risk than women who are likely to choose the self-service option.

H3b: Men who are likely to choose the full-service option will evaluate different dimensions of risk than women who are likely to choose the full-service option.

\section{METHODOLOGY}

Fifteen service situations, ranging from baggage handling at the airport to withdrawing money from a bank account were selected based on whether the situation lent itself to self- versus full-service options and whether 'typical' consumers could be expected to have knowledge of, or experience with, the situation (see Table 1 for a complete list of scenarios). Scenarios and questionnaire items were identical for each situation, except for differences in names of the scenarios and the descriptive phrases used to represent each of the self- and full-service options. '(Name) Scenario: You want to (activity). You have a choice of (self-service option) or (full-service option). So, your choices are to either (self-service option) or (full-service option)'. After being given the description of the scenario, respondents were asked to indicate likelihood of selection of choosing each service option (where $1=$ very likely and $9=$ not at all likely).

Dimensions of risk previously demonstrated to influence choice (financial, performance, psychological, social, physical, and time loss risk) were utilised..$^{38,39}$ For the study, risk was operationalised using these dimensions, plus a measure of overall risk. Using a nine-point scale (where $1=$ very risky and $9=$ not at all risky), each participant was provided with three service situations then, for each situation, asked to rate the level of risk associated with each of the dimensions. Finally, each respondent was asked to answer demographic questions, including gender, age, household income, 
profession, education and ethnicity. (See Appendix A for a representative scenario, measures of likelihood of selection, and measures of risk).

One hundred and fifty questionnaires, containing three different scenarios each, were distributed to a convenience sample of students and non-students at an urban, southern US university. Of the 450 scenarios distributed (15 scenarios $\times 30$ respondents each), 315 were completed and returned (response rate $=70$ per cent), with all scenarios adequately represented. Response rates for each scenario can be found in Table 1 .

\section{ANALYSIS AND RESULTS}

A series of regressions was performed to test the hypotheses that likelihood of choice for a self- versus full-service option would be influenced by assessments of risk (H1a, H1b) and gender-based differences in information processing ( $\mathrm{H} 2 \mathrm{a}, \mathrm{H} 2 \mathrm{~b}, \mathrm{H} 3 \mathrm{a}, \mathrm{H} 3 \mathrm{~b}$ ).

Stepwise regression analysis was used to test these relationships. The relationship between likelihood of choice and selfand full-service dimensions of risk ( $\mathrm{H} 1 \mathrm{a}$, $\mathrm{H} 1 \mathrm{~b})$ was examined using all data.

Subsequent analyses were performed after data were split by gender.

\section{Hypothesis 1}

Results of the data analysis indicate that risk dimensions associated with both of the modes of delivery influenced likelihood of choice for self- and full-service options. Thus, Hypotheses 1a and $1 \mathrm{~b}$ are supported. When asked the question (H1a), 'What is the likelihood that you would choose (self-service option)', more than 20 per cent of variation in response (Adj. $R^{2}=.214$, $p<.05)$ was explained by the following dimensions of risk: overall risk, performance risk, and psychological risk of self-service (which were inversely related to service choice), and psychological risk, social risk, and physical risk of full-service (which were positively related to service choice). The regression equation for Hypothesis $1 \mathrm{a}$ is shown in Table 2.

When asked the question (H1b), 'What is the likelihood you would choose (full-service option)', nearly one quarter of variation in response (Adj. $\left.R^{2}=.241, p<.05\right)$ was explained by: performance risk, psychological risk, physical risk and overall risk of self-service, and social risk and overall risk of full-service. Interestingly, while likelihood of choice for the self-service option (H1a) was negatively influenced by self-service dimensions of risk, and positively influenced by full-service dimensions of risk, for the full-service option (H1b), both full- and self-service dimensions of risk were negatively related to likelihood of service choice. As hypothesised ( $\mathrm{H} 1 \mathrm{~b})$, risk dimensions associated with both self- and full-service modes of delivery were considered by those likely to choose the full-service option (Table 2).

\section{Hypotheses 2 and 3}

Men who were likely to choose the full-service option evaluated a limited number of risk dimensions $(n=3)$, while women who were likely to choose the full-service option evaluated a greater number of dimensions when making a choice decision $(n=5)$ (H2b).

Men who chose the full-service option were influenced by psychological risk of self-service, overall risk of full-service, and overall risk of self-service (Adj. $\left.R^{2}=.255\right)$.

Women who chose the full-service option were influenced by psychological risk of self-service, overall risk of self-service, performance risk of 
The self- versus full-service decision: Gender-based differences in assessment of risk

Table 2: Regression analysis: Likelihood of service choice

\begin{tabular}{lcrc}
\hline Self-service option (H1a) & Std. Beta & t & Sig. \\
\hline Model & 6.995 & 20.201 & 0.000 \\
(Constant) & -0.279 & -4.036 & 0.000 \\
Overall risk of self-service & 0.136 & 2.154 & 0.032 \\
Psychological risk of full-service & -0.173 & -2.864 & 0.004 \\
Performance risk of self-service & -0.249 & -3.733 & 0.000 \\
Psychological risk of self-service & 0.173 & 2.540 & 0.012 \\
Social risk of full-service & 0.125 & 2.375 & 0.018 \\
Physical risk of full-service & & & 0.000 \\
Full-service option (H1b) & 4.202 & 12.392 & 0.002 \\
(Constant) & 0.188 & 3.076 & 0.000 \\
Performance risk of self-service & 0.295 & 4.264 & 0.001 \\
Psychological risk of self-service & -0.223 & -3.511 & 0.016 \\
Social risk of full-service & -0.139 & -2.418 & 0.001 \\
Overall risk of full-service & 0.247 & 3.313 & 0.004 \\
Overall risk of self-service & -0.183 & -2.908 & \\
Physical risk of self-service & & & \\
\hline
\end{tabular}

self-service, physical risk of self-service and social risk of full-service (Adj. $\left.R^{2}=.233\right)$. Hypotheses $2 \mathrm{~b}$ and $3 \mathrm{~b}$ were supported.

Hypothesis 2a was not supported by the data. Table 3 shows that men who were likely to choose the self-service option evaluated more risk dimensions $(n=3)$ than women who chose the self-service option $(n=2)$. Dimensions of risk that influenced men's choice of the self-service option, however, differed from those used by women, providing support for Hypothesis 3a. Among male respondents, psychological risk had the greatest effect on likelihood of choosing the self-service option, followed by performance risk, psychological risk of self-service, psychological risk of full-service and performance risk of self-service (Adj. $R^{2}=.282$ ). For women, only overall risk of self-service and social risk of full-service were shown to influence likelihood of choosing the self-service option (Adj. $R^{2}=.154$ ). For men, choice of the full-service option was positively influenced by self-service dimensions of risk (overall and psychological risk), and negatively influenced by overall risk of full service.
Similarly, for the self-service option, the psychological risk of full-service was positively associated and self-service dimensions negatively associated with men's choice. These results are consistent with women's choice of the self-service option, where overall risk of self-service was inversely related and social risk of full-service positively related. For the full-service option, however, social risk of full-service was negatively associated with women's likelihood of choice. The data suggest that men and women evaluate different risk dimensions when selecting a service option. In addition, unlike men, women's choice of the service option may be inversely related to both self- and full-service dimensions of risk.

Not surprisingly, gender also influenced perceptions of risk across individual scenarios. Perhaps some of the differences can be explained by experience of a service, the particular services chosen for the study, or as the consequence of social norms. For example, men's perceived level of risk for self-service hair colour was significantly greater than women for several dimensions: performance risk of 
Table 3: Regression analysis: Likelihood of service choice by gender

\begin{tabular}{lrrr}
\hline $\begin{array}{l}\text { Gender = Male } \\
\text { Self-service option (H2a and H3a) } \\
\text { Model }\end{array}$ & Std. Beta & t & Sig. \\
\hline (Constant) & 7.792 & 16.537 & 0.000 \\
Psychological risk of self-service & -0.431 & -5.195 & 0.000 \\
Psychological risk of full-service & 0.244 & 3.152 & 0.002 \\
Performance risk of self-service & -0.235 & -3.009 & 0.003 \\
Full-service option (H2b and H3b) & & & 0.000 \\
(Constant) & 4.245 & 10.202 & 0.004 \\
Psychological risk of self-service & 0.285 & 0.000 \\
Overall risk of full-service & -0.393 & -5.080 & 0.016 \\
Overall risk of self-service & 0.239 & 2.445 & \\
& & & 0.000 \\
Gender = Female & & & 0.000 \\
Self-service option (H2a and H3a) & 6.677 & 0.012 \\
(Constant) & -0.438 & 17.014 & \\
Overall risk of self-service & 0.199 & -5.618 & 0.000 \\
Social risk of full-service & & 2.556 & 0.003 \\
Full-service option (H3a and H3b) & 4.150 & & 0.048 \\
(Constant) & 0.287 & & 0.000 \\
Psychological risk of self-service & 0.194 & 9.765 & 0.001 \\
Overall risk of self-service & 0.305 & 0.002 \\
Performance risk of self-service & -0.278 & 3.063 & \\
Physical risk of self-service & -0.263 & 1.997 & \\
Social risk of full-service & & -3.669 & \\
\hline
\end{tabular}

self-service $(p<.000)$, social risk of self-service $(p<.05)$ and overall risk of self-service $(p<.05)$. While the objective of the current study was to explore the proposed relationship between gender, perceived risk and preference for a service alternative, these findings clearly suggest a need for further examination.

\section{DISCUSSION}

The results provide support for gender-based differences in assessment of risk. Data also suggest that consumers evaluate the risks associated with both service options when making the choice decision and that different risk dimensions are used by individuals who choose the self-service option compared with those who choose the full-service option. Finally, it appears that men's choices are influenced by risk dimensions that differ from those used by women.
When making choices, individuals evaluate aspects of risks associated with both self- and full-service options. In other words, the 'pros' and 'cons' of the alternatives are weighed before making a decision. While all dimensions of risk do not appear to be evaluated, those that are relevant for all available options are considered. In addition, similar patterns of evaluation are demonstrated across the self- and full-service options. In the present study, six determinants of risk influenced the self-service choice decision, and six determinants of risk affected the full-service decision. Furthermore, the dimensions considered across both options are essentially the same. The main difference is that those who choose the self-service option are shown to evaluate the psychological risk of both service alternatives, while those who choose the full-service 
option are only influenced by psychological risk associated with the self-service option.

For the practitioner, the results suggest that marketing communications should incorporate aspects of risk that are associated with each of the available service options, regardless of the desired outcome. For example, messages designed to increase customers' willingness to do more for themselves should present explicit (or strong implicit) information about the risks associated with self- and full-service options. Similarly, full-service providers should also incorporate components of risk for both self- and full-service modes of delivery in their communications. While messages might be tailored to influence choice of one option or another, companies could facilitate, and even guide, customers' evaluation of information.

For instance, if a banking institution wanted to encourage patrons to complete transactions using the ATM machine (self-service option) as opposed to a teller transaction (full-service option), its marketing department could apply this research in the following manner. First, the bank should focus its advertisements and brochures on reassuring the customer that transactions performed through the ATM are reliable and of little risk. The consumer needs to be convinced that the ATM transaction is safe and simple perhaps even more so than a teller transaction. Further, psychological and social issues need to be addressed. The bank might communicate to its customers that they will be viewed as old fashioned and out-of-date if they choose a teller transaction, but will be perceived as cutting edge if they choose an ATM transaction. Also, employees need to be trained to convey similar messages to customers when selling the services of the bank. When a customer is opening an account, the bank employee needs to present messages consistent with those previously discussed. If someone is completing a teller transaction, the teller could explain that this transaction could have been completed just as easily and reliably through the ATM and that this is how many customers choose to do their banking. By presenting current and/or potential customers with integrated marketing communications utilising all aspects of the promotional mix, they can be exposed to marketing messages that should lead them to make the selfversus full-service choice that the company desires.

In the previous example, the bank was essentially 'helping' the consumer make what the bank considered to be the correct self- versus full-service choice. The bank could, however, simply present the facts regarding what have been shown to be the relevant dimensions of risk (see Table 2) and allow the consumer to evaluate these dimensions and arrive at his or her own service decision.

When analysing the results for Hypotheses 2 and 3, it becomes apparent that men are more concerned with risks associated with psychological issues, while women's decisions are more likely to be influenced by social concerns. In general, men are also likely to make decisions based on objective dimensions of risk (eg overall risk, performance risk), while women are likely to consider both objective and subjective components of risk (eg overall risk, social risk), and demonstrate a greater tendency to evaluate externally-oriented information.

As hypothesised ( $\mathrm{H} 2 \mathrm{~b})$, men who choose the full-service option are less likely than women to engage in the comprehensive information processing and are, instead, more likely to use a single or limited number of salient cues when making choice decisions. For women who prefer the full-service 
option, the findings are also consistent with the selectivity model (H3b).

Women use a comprehensive information processing strategy and are likely to consider numerous cues when evaluating risks associated with a choice decision.

For the self-service option, however, results are not entirely consistent with the model of gender-based differences in information processing. While men who preferred the self-service option were shown to evaluate a limited number of risk dimensions (H2a), women who preferred the self-service option also evaluated only a limited, albeit different, number of risk dimensions (H3a). It is conceivable that these findings are a consequence of a given gender's experience with the service categories chosen for the study, since expertise has been shown to influence assessments of risk. ${ }^{40}$ It is also possible, however, that the outcomes are indicative of diminishing differences in the socialisation of men and women.

When gender is used as a basis for market segmentation, the results suggest that service providers can tailor marketing efforts utilising these differences in information processing. Although it is demonstrated that components of risk for both self- and full-service options are considered, men are likely to consider whether or not they can perform the function or if it is consistent with their self-image, while women are likely to consider how their actions will be perceived by others.

As a result, the previously discussed banking institution could further target its marketing communications based on these gender differences. For instance, if the bank wanted to target males in hopes of swaying them towards ATM transactions, it would emphasise how the use of the ATM is more in line with the male's self-image. An ATM-using man is cutting edge and technologically savvy (assuming that this is the self-image that most men perceive). Conversely, when targeting the female consumer with respect to the same decision, the marketing communications should focus on the social risk of the full-service option. Perhaps, pose the question as to what her friends would think if they saw her waiting in the bank teller line. Would they think she was mentally incapable of completing an ATM transaction? Would they think that her job was so undemanding that she could spend time waiting in a queue to complete a simple transaction?

If the same bank was trying to convince its male and female customers to choose the full-service (teller) option, once again gender-specific marketing communications could be developed. The message to male consumers would once again focus on psychological risk. This time, however, the message should convey that the highest levels of psychological risk are associated with the ATM transaction. Perhaps men who choose ATM transactions do not care about their money and finances. Further, an emphasis on the overall risk of the ATM transaction should be a focus. The marketing communications targeted towards females should be more involving given that women have been shown to rely on a greater number of dimensions when making this choice. The bank must illustrate to its female consumers that choosing the teller transaction has a lower level of social risk (eg friends will view them more favourably) while at the same time conveying that the psychological (eg the ATM transaction is not in line with her self-image), performance (eg problems are more likely to occur with an ATM transaction), physical (eg as a woman, it is safer to come inside the bank than stand on the street to 
complete a financial transaction) and overall risk are higher with an ATM transaction.

Future research needs to examine the influence of risk on self- versus full-service decisions. As suggested by the current study, gender and risk play an important role in that choice.

Interestingly, financial risk and time loss risk are not shown to influence men's or women's choice of service option. The results highlight the need for additional research on gender-based differences in assessments of risk in services settings. For instance, given that the models explained one quarter to one third of the variation in choice of service preference, future research could explore other key determinants with the goal of developing a comprehensive model. A better understanding of how risk is evaluated across self- and full-service alternatives could assist managers and provide basic guidelines for gender-based segmentation strategies. Particular attention should be given to incorporating other variables such as involvement and experience into the self- versus full-service decision. Researchers are also encouraged to investigate Internet-based service scenarios given the growing importance of this mode of retailing.

\section{References}

1 Greengard, S. (1998) 'Building a self-service culture that works', Workforce, Vol. 77, No. 7, pp. 60-64.

2 Heresniak, E. J. (1997) 'Self-service that's out-of-service', Across the Board, Vol. 34, No. 1, p. 17.

3 Ibid.

4 lnes, F. and Hansen, H. (2001) 'The potential hazard of self-service in developing customer loyalty', Journal of Service Research, Vol. 4, No. 2, pp. 79-90.

5 Lovelock, C. H. and Young, R. F. (1979) 'Look to consumers to increase productivity', Harvard Business Review, pp. 168-178, May-June.

6 Bateson, J. E. G. (1983) 'The self-service customer: Empirical findings', in 'Proceedings of the American Marketing Association', American Marketing Association, Chicago, IL, pp. 50-53.

7 Lusch, R. F., Brown, S. W. and Brunswick, G. J.
(1992) 'A general framework for explaining internal vs. external exchange', Journal of the Academy of Marketing Science, Vol. 20, No. 2, pp. 119-134.

8 Roselius, T. (1971) 'Consumer rankings of risk reduction methods', Journal of Marketing, Vol. 35, pp. 55-61, January.

9 Guseman, D. S. (1981) 'Risk perception and risk reduction in consumer services', in Donnelly, J. and George, W. R. (eds) 'Marketing of services', American Marketing Association, Chicago, IL, pp. 200-204.

10 Murray, K. B. and Schlacter, J. L. (1990) 'The impact of services versus goods on consumers' assessment of perceived risk and variability', Journal of the Academy of Marketing Science, pp. 51-65, Winter.

11 Roselius (1971) op. cit.

12 Taylor, J. W. (1974) 'The role of risk in consumer behavior', Journal of Marketing, Vol. 38, pp. 54-60, April, p. 54.

13 Roselius (1971) op. cit.

14 Guseman (1981) op. cit.

15 Murray and Schlacter (1990) op. cit.

16 Wallach, M. and Kogan, N. (1959) 'Sex differences and judgment processes', Journal of Personality, Vol. 27, pp. 555-564.

17 Cox, D. F. and Bauer, R. A. (1964) 'Self-confidence and persuasability in women', Public Opinion Quarterly, Vol. 28, pp. 453-466.

18 Burstein, B., Bank, L. and Jarvik, L. (1980) 'Sex differences in cognitive functioning: Evidence, determinants, implications', Human Development, Vol. 23, pp. 289-313, August.

19 Holbrook, M. B. (1986) 'Aims, concepts and methods for the representation of individual differences in esthetic responses to design features', Journal of Consumer Research, Vol. 13, pp. 337-347, December.

20 Meyers-Levy, J. and Maheswaran, D. (1991) 'Exploring differences in males' and females' processing strategy', Journal of Consumer Research, Vol. 18, pp. 63-70, June.

21 Meyers-Levy, J. (1994) 'Gender differences in cortical organization: Social and biochemical antecedents and advertising consequences', in Clark, E., Brock, T. and Stewart, D. (eds) 'Attention, attitude and affect in response to advertising', Lawrence Erlbaum Associates, Hillsdale, NJ, pp. 107-122.

22 Rahman, Q. (2000) 'Gender differences, "risk-taking" and the need for empiricism', Psychology, Evolution and Gender, Vol. 2, No. 2, pp. 151-155.

23 Taylor (1974) op. cit., p. 59.

24 Meyers-Levy, J. (1989) 'Gender differences in information processing: A selectivity interpretation', in Cafferata, P. and Tybout, A. M. (eds) 'Cognitive and affective responses to advertising', Lawrence Erlbaum Associates, Hillsdale, NJ.

25 Meyers-Levy and Maheswaran (1991) op. cit.

26 Meyers-Levy, J. and Sternthal, B. (1991) 'Gender differences in the use of message cues and 
judgements', Journal of Marketing Research, Vol. 28, pp. 84-96, February.

27 Meyers-Levy and Maheswaran (1991) op. cit

28 Darley, W. K. and Smith, R. E. (1995) 'Gender differences in information processing strategies: An empirical test of the selectivity model in advertising response', Journal of Advertising, Vol. 24, No. 1, pp. 41-57.

29 Roselius (1971) op. cit.

30 Jacoby, J. and Kaplan, L. B. (1972) 'The components of perceived risk', in 'Proceedings of the Association for Consumer Research', Association for Consumer Research, College Park, MD, pp. 382-393.
31 Kaplan, L. B., Szybillo, G. J. and Jacoby, J. (1974) 'Components of perceived risk in product purchase:

A cross-validation', Journal of Applied Psychology, Vol.

59, No. 3, pp. 287-291.

32 Murray and Schlacter (1990) op. cit.

33 Lusch, Brown and Brunswick (1992) op. cit.

34 Taylor (1974) op. cit.

35 Ibid., p. 59

36 Darley and Smith (1995) op. cit. p. 45.

37 Ibid., p. 44.

38 Roselius (1971) op. cit.

39 Jacoby and Kaplan (1972) op. cit.

40 Taylor (1974) op. cit.

\section{APPENDIX A (SCENARIO = BANK WITHDRAWAL)}

You want $\$ 50$ withdrawn from your checking account. You have a choice of using the ATM or using the bank teller. There are equally short waiting times for either option. So your choices are to either use the ATM or use the bank teller.

Circle one response per question.

1. What is the likelihood that you will use the ATM?

$\begin{array}{ccccccccc}1 & 2 & 3 & 4 & 5 & 6 & 7 & 8 & 9 \\ \text { Very Unlikely } & & & & & & & & \text { Very Likely }\end{array}$

2. What is the likelihood that you will use the teller?
Very Unlikely
$4 \quad 5 \quad 6$
$\begin{array}{lll}7 & 8 & 9\end{array}$
Very Likely

3. What is the likelihood that it will cost more to use the teller than using the ATM?
1
3
4
56
7
89
Very Unlikely
Very Likely

4. What is the likelihood that it will require more effort on your part to use the ATM than to use the teller?
Very Unlikely
34
5
6
7
89
Very Likely

5. What is the likelihood that the teller will take more time than using the ATM?
Very Unlikely
23
4
56
78
Very Likely

6. What is the likelihood that the ATM will not work properly?

$\begin{array}{llllllllc}1 & 2 & 3 & 4 & 5 & 6 & 7 & 8 & 9 \\ \text { Very Unlikely } & & & & & & & & \text { Very Likely }\end{array}$

7. What is the likelihood that something will go wrong if you use the teller?
12
23
34
45
56
7
8
Very Unlikely
Very Likely 
The self- versus full-service decision: Gender-based differences in assessment of risk

8. How likely is it that the ATM could be harmful or injurious to you?

$$
\begin{array}{cccccccccc}
1 & 2 & 3 & 4 & 5 & 6 & 7 & 8 & 9 \\
\text { Very Unlikely } & & & & & & & & \text { Very Likely }
\end{array}
$$

9. How likely is it that using the teller could be harmful or injurious?

$\begin{array}{ccccccccc}1 & 2 & 3 & 4 & 5 & 6 & 7 & 8 & 9 \\ \text { Very Unlikely } & & & & & & & & \text { Very Likely }\end{array}$

10. What are the chances that using the ATM will not fit your self-image or self-concept (i.e., the way you think about yourself)?

$\begin{array}{ccccccccc}1 & 2 & 3 & 4 & 5 & 6 & 7 & 8 & 9 \\ \text { Very Unlikely } & & & & & & & \text { Very Likely }\end{array}$

11. What are the chances that using the teller will not fit your self-image or self-concept?

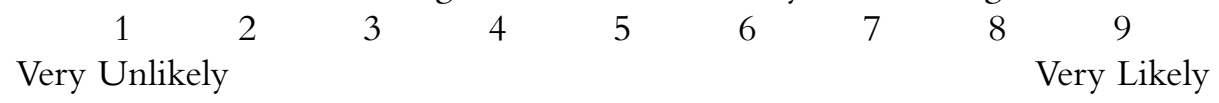

12. What are the chances that using the ATM will affect the way others think of you?
12
3
45
6
7
89
Very Unlikely
Very Likely

13. What are the chances that using the teller will affect the way others think of you?

$\begin{array}{ccccccccc}1 & 2 & 3 & 4 & 5 & 6 & 7 & 8 & 9 \\ \text { Very Unlikely } & & & & & & & & \text { Very Likely }\end{array}$

14. Overall, considering all factors, how risky is it to use the ATM?

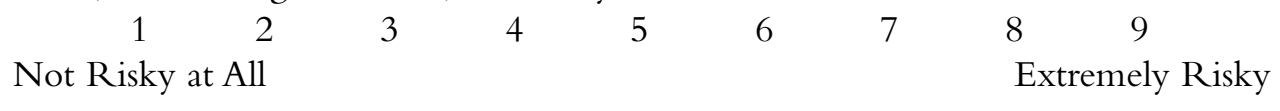

15. Overall, considering all factors, how risky is it to use the teller?
Not Risky at All
$\begin{array}{lr}1 & 2 \\ \text { isky at All }\end{array}$
34
5
6
7
89
Extremely Risky 